\title{
Steady Rheological Properties of Rotating Biological Contactor (RBC) Sludge
}

\author{
Basim ABU-JDAYIL ${ }^{1}$, Fawzi BANAT ${ }^{2}$, Mukheled AL-SAMERAIY ${ }^{2}$ \\ ${ }^{1}$ Department of Chemical \& Petroleum Engineering, U.A.E. University, Al-Ain, U.A.E. \\ ${ }^{2}$ Department of Chemical Engineering, Jordan University of Science and Technology, Irbid, Jordan \\ E-mail:Babujdayil@uaeu.ac.ae \\ Received October 11, 2009; revised October 23, 2009; accepted December 8, 2009
}

\begin{abstract}
The rheological characterization of sewage sludge at different steps of wastewater treatment is important since it allows predicting and estimating sludge behavior when submitted to almost all treatment and disposal operations. Rotating biological contactor (RBC) is being widely used for wastewater treatment, which is a biological treatment process following primary treatment. The rheological characterization of RBC sludge at different solid contents $(\mathrm{TSS}=32.2 \mathrm{~g} / \mathrm{L}-50.2 \mathrm{~g} / \mathrm{L})$ and temperatures $\left(5-40{ }^{\circ} \mathrm{C}\right)$ was carried out using a rotational viscometer. The RBC sludge showed a shear-thinning behavior, where the apparent viscosity decreased rapidly with the shear rate reaching the limiting viscosity $\left(\eta_{\infty}\right)$ at the infinite shear rate. An exponential relationship described the evolution of the limiting viscosity with the sludge TSS content. In addition, a dramatic increase in the limiting viscosity beyond a TSS concentration of $42.4 \mathrm{~g} / \mathrm{L}$ has been observed. On the other hand, Bingham model described well the non-Newtonian behavior of sludge suspensions. It was clear that the yield stress is more sensitive than the Bingham viscosity for the variation in temperature and solid content. However, the rheological results revealed that both the limiting and Bingham viscosities have the same behavior with the TSS content and with the temperature.
\end{abstract}

Keywords: Sludge Rheology, Activated Sludge, RBC Sludge, Bingham Fluid, Limiting Viscosity

\section{Introduction}

Wastewater treatment process generates significant quantities of sludge from suspended solid in the feed, biomass generated by biological operations, and precipitates from added chemicals. Since solid concentration is often below $5 \%$, large volumes of sludge must be handled. Sludge handling and disposal typically constitute 25 to $40 \%$ of the total cost of wastewater treatment plant [1]. Raw sludge is an unstable solids suspension that must be subjected to specific and complex treatment before an environmentally acceptable product is obtained for final disposal. In a conventional activated sludge wastewater treatment plant, raw sludge is normally a mixture of the primary sludge and the excess biological sludge. In general, raw sludge has about $3-5 \%$ by weight total solids, among which about $70-80 \%$ is organic matter. Due to its high organic solids content, raw sludge must be stabilized by digestion processes in order to ob- tain a stable product that is easier to handle and to dispose. During the anaerobic digestion, heterotrophic bacteria reduce about $40-50 \%$ of the organic compounds, especially those less complex and readily biodegradable. These compounds are normally insoluble and of colloidal form and may be classified as a complex mixture of nutrients, proteins, carbohydrates and organic acids. The biological assimilation of these solids reduces slightly the total solid concentration of the sludge but certainly changes the rheological properties of the digested sludge [2].

The rheological characterization of sewage sludge at different steps of wastewater treatment is important since it allows predicting and estimating sludge behavior when submitted to almost all treatment and disposal operations. In reality, the knowledge of rheological properties helps in the selection of the most proper equipment and procedure to be adopted. Rheological parameters are very important in sludge management, not only as designing parameters in transporting, storing, landfill and spreading 
operations, but also as controlling ones in many treatments, such as stabilization and dewatering [3].

At the moment, rheological parameters are essentially used in sludges conditioning or for optimizing sludge consistency for the storage, spreading [4-6] and as indicators of sludge quality in aeration tanks [7]. In addition, Hasar et al. [8] have pointed out that the activated sludge viscosity has a major impact on pressure loss in pipes, transport phenomena near the membrane and sludge conditioning in next step.

The rheological characteristics of sludge depend on many factors such as source, solid concentration, temperature, and sludge treatment method [3,8,9] showed that rheological parameters are strongly dependent on the sludge type and total solid content. Battistoni et al. [10] has also observed that sludge rheology is strongly dependent on feed characteristics and conditions applied. Rotating Biological Contactor (RBC) is being widely used for wastewater treatment but there is an apparent lack of knowledge about the rheological properties of the produced sludge. A rotating biological contactor or RBC is a biological treatment process used in the treatment of wastewater following primary treatment, which removes the grit and other solids through a screening process followed by a period of settlement. The RBC process involves allowing the wastewater to come in contact with a biological medium at the rotating biological cofactors in order to remove pollutants from the wastewater. A rotating biological contactor consists of a series of closely spaced, parallel discs mounted on a rotating shaft which is supported just above the surface of the waste water. Microorganisms grow on the surface of the discs where biological degradation of the wastewater pollutants takes place. The constant rotation of the disc causes mixing of the liquid, while the rotating disc surface alternately comes into contact between air and wastewater and thus acts as an aeration device for wastewater treatment. However, the basis of the practical use of the RBC is that the dissolved oxygen in the reactor did not have significance on treatment efficiency because sufficient amount of oxygen could be supplied during the air exposure cycle [11].

The objective of this work was to study the rheological characteristics of sewage sludge generated from Rotating Biological Contactors (RBC) technology. The effects of the temperature and the solid content on the rheological parameters of RBC sludge were investigated. Since the sludge samples were collected from the sludge tank that comes after the RBC unit, the rheological characterization presented here can be used to improve the storage and transportation system of the RBC sludge and the conditioning process.

\section{Materials and Methods}

\subsection{Sludge Sample and Treatment Plant}

The Sludge samples were collected from a wastewater treatment plant located in the campus of Jordan University of Science and Technology (JUST) and thereafter they were stored in a refrigerator at a temperature of $8{ }^{\circ} \mathrm{C}$ before being used in the tests. The sludge samples were collected from the sludge tank that comes after the RBC unit.

Wastewater from the General Services Buildings, King Abdullah Hospital, Student and Staff Housing are collected and treated at the JUST wastewater treatment plant. The average biological oxygen demand (BOD) of wastewater is about $400 \mathrm{mg} / \mathrm{L}$. The BOD of the treated wastewater is no more than $10 \mathrm{mg} / \mathrm{L}$. Wastewater passed through several steps of treatment, including physical as well as biological steps. Six rotating biological contactors (RBC) are used in the bio-treatment step. The RBC contactors are made from plastic discs supported on a shaft passing perpendicularly through the center of each disc. The discs are slowly rotated at $1.25 \mathrm{rpm}$ in a contour-bottomed tank containing the wastewater. As the surfaces of the discs are alternately exposed to the wastewater and air, biological growth forms these surfaces. The biological growth will adsorb and assimilate the organic materials in solution. Air is also supplied to the wastewater in the tank to further increase the growth of bacteria. Excess biomass is sloughed off by shearing as the growth passes through the liquid and is kept in suspension by the mixing of the discs. The treated wastewater flows out of the tank into a clarifier to remove the suspended solids. The clarified wastewater was chlorinated before being pumped to the university lake to be used for irrigation purposes. The remaining solids and water in the clarifier, i.e. sludge, is pumped to the sludge tank as shown in Figure 1. Sludge samples tested in this work were collected from the bottom of the sludge tank.

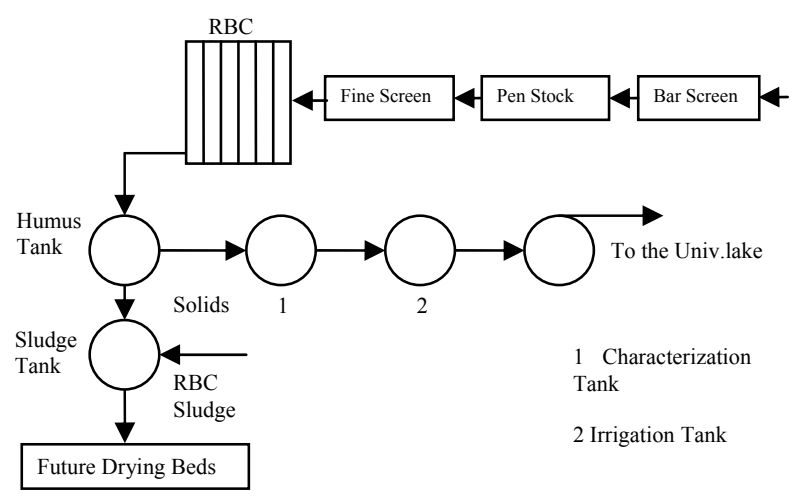

Figure 1. Block diagram for JUST wastewater treatment plant. 


\subsection{Viscometer}

The steady rheological properties of RBC sludge were measured using a concentric cylinder viscometer (Haake VT 500, MV1-system), which composed of an inner cylinder rotating in a stationary outer cylinder. The radius of the rotating cylinder is $20.04 \mathrm{~mm}$, the length of the cylinder is $60 \mathrm{~mm}$, and the gap width is $0.96 \mathrm{~mm}$. For every point on the flow curves a constant shear rate was used. After attaining a constant the shear-stress signal, which required about 30 seconds, the values of shear stress and viscosity were recorded. The viscometer was thermostatically controlled with a water circulator (Haake D8) at the desired temperature.

Experiments were performed to characterize the rheological behavior of RBC sludge using flow curve measurements. A fresh sample was loaded into the annular gap of the concentric cylinder viscometer. The apparent viscosity of RBC sludge as a function of shear rate was measured.

\section{Results and Discussions}

\subsection{Effect of Total Suspended Solids}

The rheological properties of sludge material can be significantly affected by variables such as shear rate, temperature and total solids. In many cases, solid concentration was the most important parameter affecting the sludge rheology $[8,12,13]$. Sewage contains solid materials like bones, stones, wood, rages, etc, which make pumping of sewage difficult. The percentage of solids in sewage gives an indication of the concentration and physical state of its principal constitutes. The combination of inorganic and organic solids is called "total suspended solids" [14]. In this work, the effects of total suspended solids (TSS=32.2 $\mathrm{g} / \mathrm{L}-50.2 \mathrm{~g} / \mathrm{L}$ ) and temperature $\left(5-45{ }^{\circ} \mathrm{C}\right)$ on the rheological behavior of $\mathrm{RBC}$ sludge were investigated.

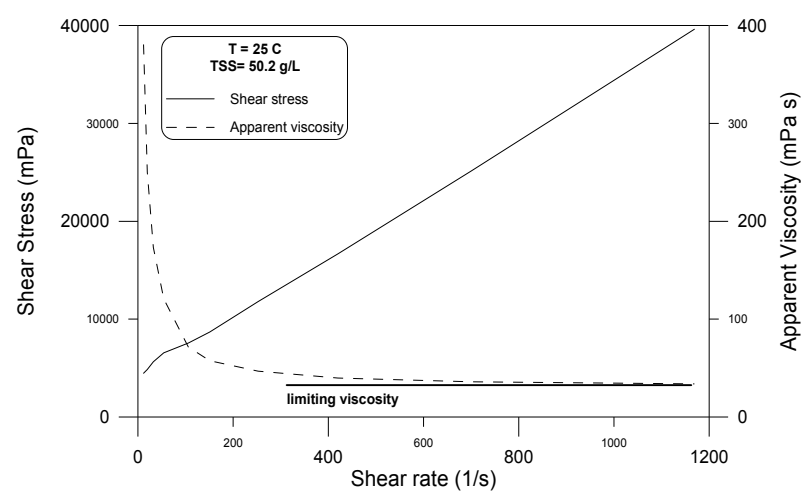

Figure 2. Typical rheological behavior of RBC sludge at TSS of $50.2 \mathrm{~g} / \mathrm{L}$ and $\mathrm{T}$ of $25^{\circ} \mathrm{C}$.
Figure 2 shows the typical rheological behavior of RBC sludge at TSS $=50.2 \mathrm{~g} / \mathrm{L}$ and temperature of $25^{\circ} \mathrm{C}$. The shear stress $(\tau)$ was measured as the shear rate $(\dot{\gamma})$ was increased from 11.7 to $1169 \mathrm{~s}^{-1}$. As illustrated in Figure 2, the RBC sludge showed a shear-thinning behavior, where the apparent viscosity $\left(\eta_{a p p}=\tau / \dot{\gamma}\right)$ decreased rapidly as the shear rate was increased, and became constant at higher shear rate reaching the limiting viscosity $\left(\eta_{\infty}\right)$ at the infinite shear rate. The limiting viscosity was associated with the optimal orientation of the sludge in the direction of flow [12].

The limiting viscosity has been widely used as a parameter for characterizing sludge rheology $[9,12,15]$. The properties of suspended solids, such as particle size, shape and density, particle-particle interaction, flocculation ability, etc, all have effects on the rheological properties of sludge $[12,15]$. Figure 3 shows that the limiting viscosity was greatly affected by the TSS content of the RBC sludge, which is in agreement with several other types of biological sludges $[9,12,15]$. An exponential relationship always describes the evolution of the limiting viscosity (rheological parameter) with the sludge TSS content, as also observed in this study. It has been indicted that the increase of the limiting viscosity of activated sludge was due to the increased interactions between the flocs at increased TSS content [9]. Figure 3 also shows a dramatic increase in the limiting viscosity beyond a TSS concentration of $42.4 \mathrm{~g} / \mathrm{L}$. In this case two different exponential equations were needed to describe the dependence of the limiting viscosity on the whole range of TSS content. The point of the strongest viscosity increase can be determined from the intersection of the two regression lines for low and high ranges of sludge solid content. This point is shown in Figure 3 as critical TSS.

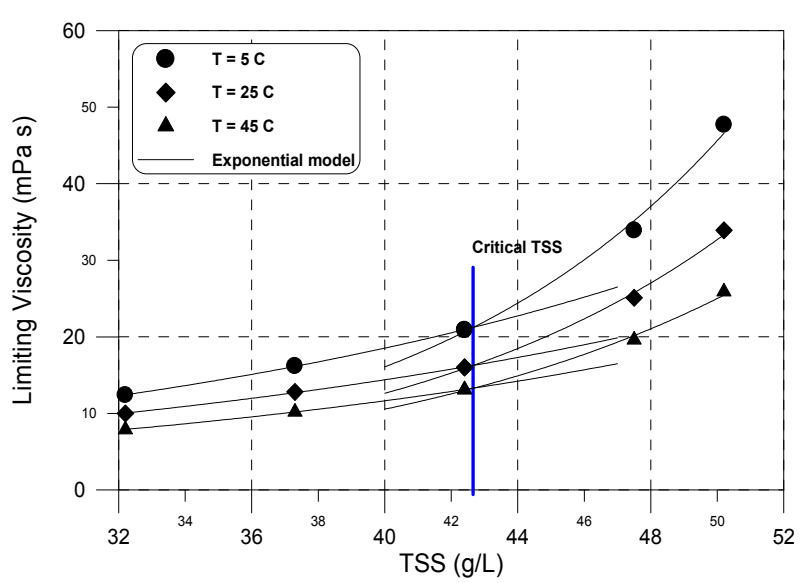

Figure 3. Limiting viscosity as a function of TSS for different temperatures. 


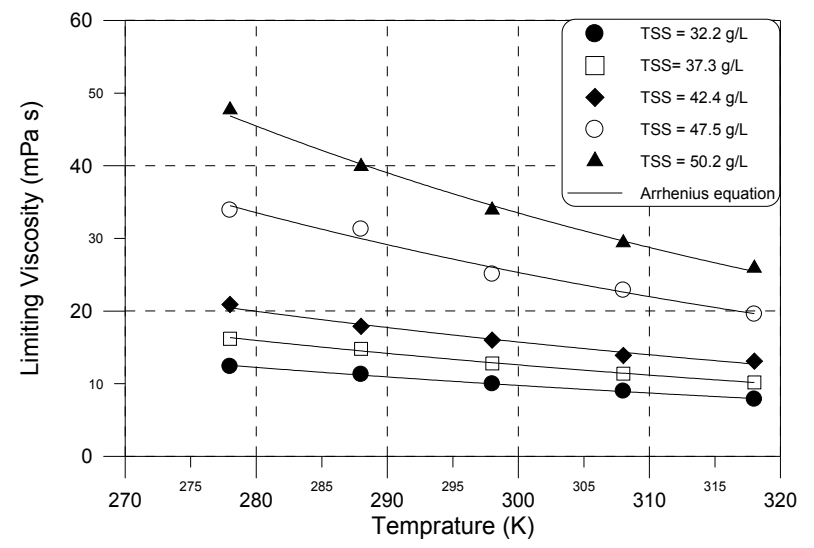

Figure 4. Limiting viscosity of RBC sludge as a function of temperature for different TSS.

\subsection{Effect of Temperature}

Moreover, temperature is another important factor affecting the limiting viscosity of RBC sludge. Figure 4 shows that the limiting viscosity decreased by increasing the temperature. The thermal motion of particles is more violent at higher temperature, and then the network strength between the particles is weekend, resulting in a decrease in viscosity [12]. The influence of temperature on the limiting viscosity can be described well by an Arrhenius type equation (see Figure 4):

$$
\eta_{\infty}=K e^{\frac{E_{a}}{R T}}
$$

where $\eta_{\infty}$ is the limiting viscosity, $K$ is pre-exponential constant, $T$ the absolute temperature, $R$ is the universal gas constant and $E_{a}$ is the limiting viscosity activation energy. Table 1 shows the regressed values of $K$ and $E_{a}$ at different TSS content. It is clear that there is small increase in $E_{a}$ with increasing the total solids. The low value of activation energy (0.094-0.127 J/ mol ) suggested low dependence of limiting viscosity of the RBC sludge on the temperature. The high regression coefficients of the above equation, which varied from 0.982 to 0.997, suggested that the Arrhenius equation was able adequately to describe the relationships between the rheology of RBC sludges and temperature.

\subsection{Rheological Modeling}

Figure 5 illustrates the flow curves of RBC sludge at different TSS values. For all investigated TSS and temperatures, the sludge samples showed shear-thinning behavior with a yield stress. Bingham model (Equation 2) has been used to describe the non-Newtonian behavior of sludge suspensions $[3,12,13]$ :

$$
\tau=\tau_{o}+\eta_{B} \dot{\gamma}
$$

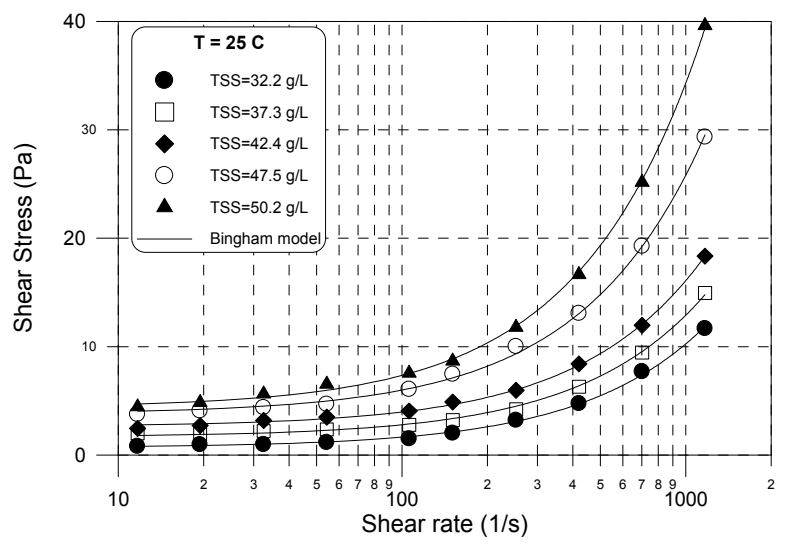

Figure 5. Flow curves of RBC sludge at different TSS.

Table 1. Regressed parameters of Equation 1.

\begin{tabular}{cccc}
\hline $\operatorname{TSS}(g / L)$ & $K($ mPa.s $)$ & $E_{a} / R(K)$ & $R^{2}$ \\
\hline 32.2 & 292 & 0.0113 & 0.997 \\
37.3 & 442 & 0.0118 & 0.996 \\
42.4 & 554 & 0.0119 & 0.983 \\
47.5 & 1730 & 0.0141 & 0.982 \\
50.5 & 3267 & 0.0153 & 0.995 \\
\hline
\end{tabular}

where $\tau$ is the shear stress, $\tau_{o}$ is the yield stress; $\eta_{B}$ is the Bingham viscosity and $\dot{\gamma}$ is the shear rate. In the sludge samples the yield stress must be reached before flow starts. Its presence is due to the resistance solid particles oppose to deformation, until the applied stress exceed the yield strength of the solid phase and that the sludge show flow. It is commonly admitted that the yield stress of suspensions is linked to the existence of an interconnected three dimensional network of flocs. The value of the yield stress corresponds to the stress needed to be applied to overcome the cohesion Van der-Waals forces and induce the flow of the suspension [15].

Figure 5 also shows the flow curves of RBC sludge for different values of TSS fitted to the Bingham model; while the model parameters obtained by non-linear regression for different TSS and temperatures are reported in Table 2. The high regressions coefficients (around 0.99) indicated that the Bingham model describe adequately the rheological behavior of RBC sludges under different conditions. As shown in Table 2, both the yield stress and Bingham viscosity decreased as the temperature was increased from 5 to $45{ }^{\circ} \mathrm{C}$. However, at a given temperature when the solid content was increased the Bingham parameters $\left(\tau_{o}, \eta_{B}\right)$ were found to increase accordingly. The obtained yield stress increased significantly from $59 \mathrm{mPa}$ at $\mathrm{TSS}=32.2 \mathrm{~g} / \mathrm{L}$ and $\mathrm{T}=45^{\circ} \mathrm{C}$ to $5520 \mathrm{mPa}$ at $\mathrm{TSS}=50.2 \mathrm{glL}$ and $\mathrm{T}=5{ }^{\circ} \mathrm{C}$. On the other hand, the Bingham viscosity exhibited less pronounced 
Table 2. Regressed parameter values of Bingham model used to describe the rheological data for different temperatures and total solid content.

\begin{tabular}{|c|c|c|c|}
\hline $\operatorname{TSS}(g / L)$ & $\begin{array}{c}\text { Temperature } \\
(K)\end{array}$ & $\begin{array}{c}\tau_{o} \\
(m P a)\end{array}$ & $\begin{array}{c}\eta_{B} \\
(m P a \cdot s)\end{array}$ \\
\hline \multirow{5}{*}{32.2} & 278.15 & 1527 & 11.0 \\
\hline & 288.15 & 1094 & 10.2 \\
\hline & 298.15 & 697 & 9.6 \\
\hline & 308.15 & 332 & 8.7 \\
\hline & 318.15 & 59 & 7.8 \\
\hline \multirow{5}{*}{37.3} & 278.15 & 2552 & 14.0 \\
\hline & 288.15 & 2123 & 12.9 \\
\hline & 298.15 & 1674 & 11.2 \\
\hline & 308.15 & 1235 & 10.4 \\
\hline & 318.15 & 929 & 9.4 \\
\hline \multirow{5}{*}{42.3} & 278.15 & 3579 & 18.1 \\
\hline & 288.15 & 3031 & 15.5 \\
\hline & 298.15 & 2630 & 13.5 \\
\hline & 308.15 & 2199 & 11.9 \\
\hline & 318.15 & 1701 & 11.4 \\
\hline \multirow{5}{*}{47.5} & 278.15 & 5033 & 29.7 \\
\hline & 288.15 & 4432 & 27.7 \\
\hline & 298.15 & 3794 & 22.0 \\
\hline & 308.15 & 3351 & 20.0 \\
\hline & 318.15 & 2980 & 17.3 \\
\hline \multirow{5}{*}{50.5} & 278.15 & 5520 & 43.0 \\
\hline & 288.15 & 4864 & 35.9 \\
\hline & 298.15 & 4354 & 30.0 \\
\hline & 308.15 & 3865 & 26.3 \\
\hline & 318.15 & 3302 & 23.5 \\
\hline
\end{tabular}

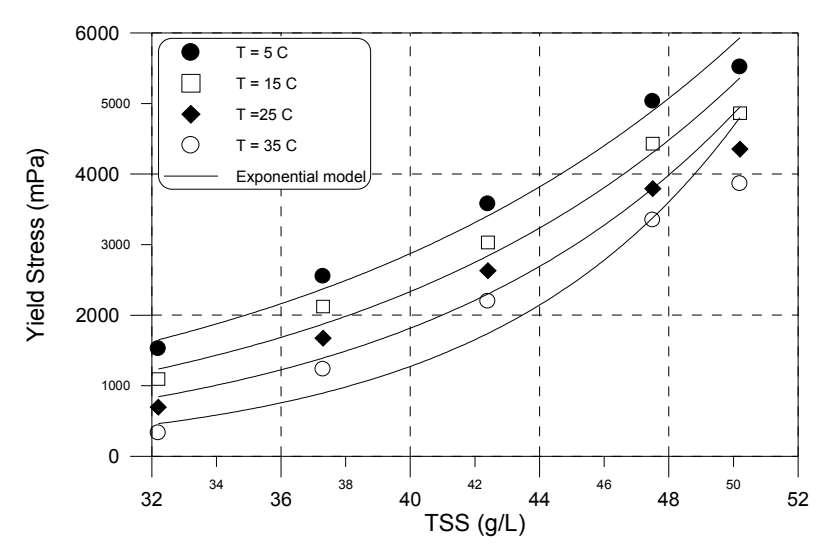

Figure 6. Dependence of the yield stress on TSS content.
Table 3. Exponential parameters of the correlation between the yield stress and the sludge TSS content.

\begin{tabular}{cccc}
\hline Temperature $\left({ }^{\circ} \mathrm{C}\right)$ & $A$ & $B$ & $R^{2}$ \\
\hline 278.15 & 167.45 & 0.071 & 0.982 \\
288.15 & 89.58 & 0.082 & 0.970 \\
298.15 & 35.55 & 0.098 & 0.952 \\
308.15 & 7.00 & 0.130 & 0.921 \\
318.15 & 0.19 & 0.204 & 0.835 \\
\hline
\end{tabular}

Table 4. Regressed parameters of Equation 4.

\begin{tabular}{cccc}
\hline TSS $(g / L)$ & $C(\mathrm{mPa})$ & $E_{y} / R(K)$ & $R^{2}$ \\
\hline 32.2 & $4.3 \times 10^{12}$ & 0.077 & 0.887 \\
37.3 & $3.2 \times 10^{6}$ & 0.025 & 0.991 \\
42.4 & $5.6 \times 10^{5}$ & 0.018 & 0.987 \\
47.5 & $2.0 \times 10^{5}$ & 0.013 & 0.998 \\
50.5 & $1.8 \times 10^{5}$ & 0.013 & 0.996 \\
\hline
\end{tabular}

evolution, where it increased from $7.8 \mathrm{mPa} \cdot \mathrm{s}$ at TSS $=32.2 \mathrm{~g} / \mathrm{L}$ and $\mathrm{T}=45^{\circ} \mathrm{C}$ to $43 \mathrm{mPa} \cdot \mathrm{s}$ at TSS $=50.2 \mathrm{glL}$ and $\mathrm{T}=5{ }^{\circ} \mathrm{C}$. It is clear that the yield stress is more sensitive than the Bingham viscosity for the variation in temperature and solid content.

An exponential law (Equation 3) can describe the relationship between the yield stress and the TSS content on the entire range of TSS investigated, see Figure 6:

$$
\tau_{o}=A e^{(B[T S S])}
$$

Table 3 shows the values obtained form the application of the exponential model for different sludge temperatures. It is clear that the deviation from the exponential behavior increased with increasing the temperature.

In addition, the effect of temperature on the yield stress of the RBC sludge can be also well described by the Arrhenius equation type, see Figure 7:

$$
\tau_{o}=C e^{\frac{E_{y}}{R T}}
$$

where $C$ is the pre-exponential constant, and $E_{y}$ is the yield stress activation energy. Table 4 shows the regressed parameters of Equation 4.

The evolution of the Bingham viscosity $\left(\eta_{B}\right)$ with the TSS content followed the same trend of the limiting viscosity, where a dramatic increase in the Bingham viscosity beyond a TSS concentration of $42.4 \mathrm{~g} / \mathrm{L}$ was observed, see Figure 8. Several authors $[16,17]$ have shown that on a weak TSS variation range (about $4 \mathrm{~g} / \mathrm{L}$ of variation), 
the evolution of Bingham parameters can be described by a linear law. The particle-particle interactions increase with TSS content and thus increase drastically the Bingham viscosity as well as the rheological properties of sludge [16].

On the other hand, the Arrhenius type equation well correlated the relationship between the Bingham viscosity

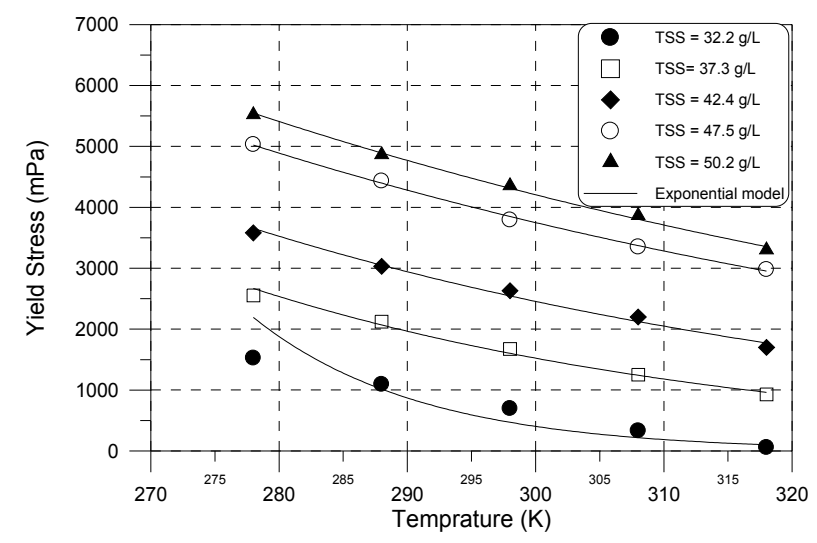

Figure 7. Dependence of the yield stress on the temperature.

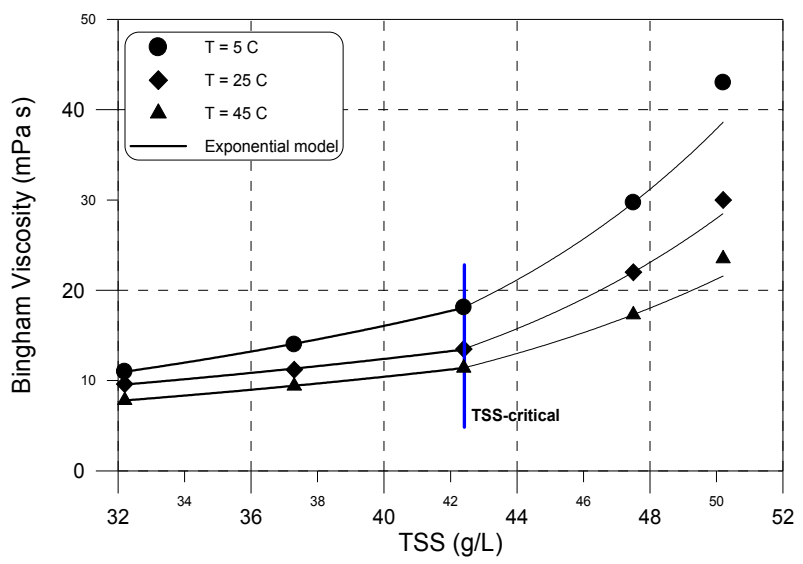

Figure 8. Dependence of the Bingham viscosity of the TSS content.

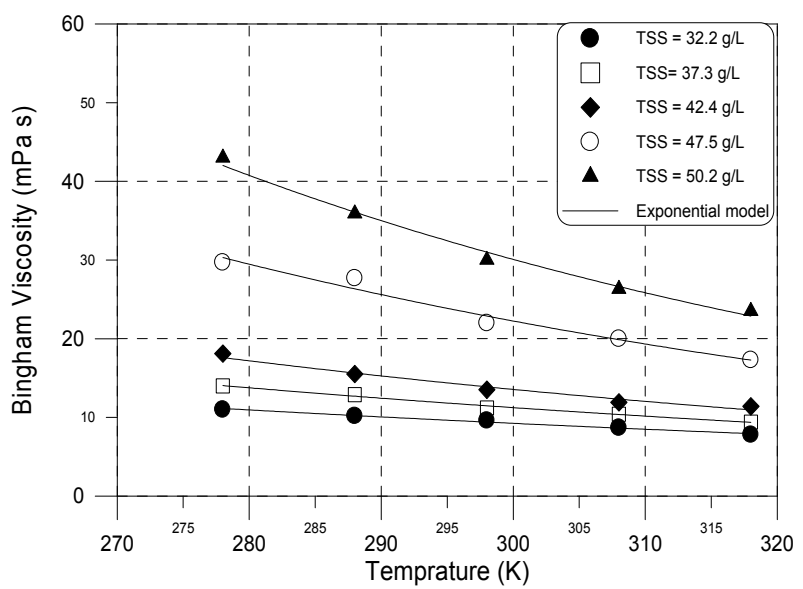

Figure 9. Dependence of the Bingham viscosity of the temperature.
Table 5. Regressed parameters of Equation 5.

\begin{tabular}{cccc}
\hline TSS $(g / L)$ & $D(m P a \cdot s)$ & $E_{B} / R(K)$ & $R^{2}$ \\
\hline 32.2 & 117 & 0.008 & 0.987 \\
37.3 & 234 & 0.010 & 0.992 \\
42.4 & 480 & 0.012 & 0.969 \\
47.5 & 1512 & 0.014 & 0.977 \\
50.5 & 2870 & 0.015 & 0.989 \\
\hline
\end{tabular}

and the temperature, see Figure 9:

$$
\eta_{B}=D e^{\frac{E_{B}}{R T}}
$$

where $D$ is the pre-exponential constant, and $E_{B}$ is the Bingham viscosity activation energy. Table 5 shows the regressed parameters of Equation 5. As evident from Tables 4 and 5, the activation energy for yield stress decreased with solid content, in contrast, the activation energy of Bingham viscosity increased. However, the activation energies of both parameters were equal at TSS content above the TSS-critical.

The results here comply with those of several authors who have shown an exponential [17-20] or power [10] law between sludge TSS content and Bingham parameters.

On the other hand, the activation energy of the Bingham viscosity varied between $0.0665 \mathrm{~J} / \mathrm{mol}$ at TSS= $32.2 \mathrm{~g} / \mathrm{L}$ and $0.125 \mathrm{~J} / \mathrm{mol}$ at TSS $=50.2 \mathrm{~g} / \mathrm{L}$, which was approximately similar to the activation energy of the limiting viscosity. Results revealed that both the limiting and Bingham viscosities have the same behavior with the TSS content and with the temperature.

\section{Conclusions}

In this work, the dependence of rheological properties of RBC sludge on solid content (TSS) and temperature has been experimentally investigated. Results revealed that the RBC sludge behaved like a Bingham fluid. The limiting viscosity and the Bingham parameters have been used to characterize the RBC sludge. An exponential relationship was employed to describe the evolution of the limiting viscosity with the sludge TSS content, and the dramatic increase in the limiting viscosity beyond a TSS concentration of $42.4 \mathrm{~g} / \mathrm{L}$. The influence of temperature on the limiting viscosity has been well described by an Arrhenius type equation. It has been found that both the yield stress and Bingham viscosity decreased as the temperature was increased from 5 to $45^{\circ} \mathrm{C}$. However, at a given temperature when the solid content was increased the Bingham parameters $\left(\tau_{o}, \eta_{B}\right)$ found to increase accordingly. It was clear that the yield stress was more sensitive than the Bingham viscosity for the variation in temperature and solid content. 


\section{References}

[1] D. Sundstorm and H. Klei, "Wastewater Treatment," Prentice Hall, NJ, 1979.

[2] P. S. Monteiro, "The influence of the anaerobic digestion process on the sewage sludge rheological behavior," Water Science and Technology, Vol. 36, pp. 61-67, 1997.

[3] V. Lotito, I. Spinosa, G. Mininni, and R. Antonacci, "Rheology of sewage sludge at different steps of treatment," Water Science and Technology, Vol. 63, pp. 79-85, 1997.

[4] L. Novak, L. Larrea, J. Wanner, and J. L. Garcia-Herras, "Non-filamentous activated sludge bulking in a laboratory scale," Water Research, Vol. 27, 1339-1346, 1993.

[5] A. C. Badino Jr, M. C. R. Facciotti, and W. Schmidell, "Estimation of the rheology of glucoamylase fermentation broth from the biomass concentration and shear conditions," Biotech Technol, Vol. 13, pp. 723-726, 1999.

[6] G. Trejo-Tapia, A. Jimenez-Aparicio, and L. Villarreal, "Rodriguez-Monroy, M. Broth rheology and morphological analysis of solanum chrysotrichum cultivated in a strirred tank," Biotech Lett, Vol. 23, pp. 1943-1946, 2001.

[7] G. Guibaud, N. Tixier, and M. Baudu, "Hysteresis area, a rheological parameter used as a tool to assess the ability of filamentous sludges to settle," Process Biochemistry, Vol. 40, pp. 2671-2676, 2005.

[8] H. Hasar, C. Kinaci, A. Ünlü, H. Togrul, and U. Ipek, "Rheological properties of activated sludge in a sMBR," Biochemical Engineering Journal, Vol. 20, pp. 1-6, 2004.

[9] A. Pevere, G. Guibaud, E. van Hullebusch, P. Lens, and M. Baudua, "Viscosity evolution of anaerobic granular sludge," Biochemical Engineering Journal, Vol. 27, pp. 315-322, 2006.

[10] P. Battistoni, G. Fava, C. Stanzini, F. Cecchi, and A. Bassetti, "Feed characteristics and digester operative conditions as parameters affecting the rheology of digested municipal solid wastes," Water Science and Technology, Vol. 27, pp. 37-45, 1993.

[11] V. Kubsad, S. Chaudhari, and S. K. Gupta, "Model for oxygen transfer in rotating biological contactor," Water Research, Vol. 38, pp. 4297-4304, 2004.

[12] Y. Mu and H. Q. Yu, "Rheological and fractal characteristics of granular sludge in an upflow anaerobic reactor," Water Research, Vol. 40, pp. 3596-3602, 2006.

[13] M. Mori, I. Seyssiecq, and N. Roche, "Rheological measurements of sewage sludge for various solids concentrations and geometry," Process Biochemistry, Vol. 41, pp. 1656-1662, 2006.

[14] S. K. Hussain, "Public Health Engineering," Technology India Publications, Satya Prakashan, 1990.

[15] I. Seyssiecq, J. H. Ferrasse, and N. Roche, "State-of-theart: Rheological characterization of wastewater treatment sludge," Biochemical Engineering Journal, Vol. 16, pp. 41-56, 2003.

[16] C. F. Forster, "The rheological and physico-chemical characteristics of sewage sludges," Enzyme Microbial Technol, Vol. 30, pp. 340-345, 2002.

[17] N. Tixier, G. Guibaud, and M. Baudu, "Determination of some rheological parameters for the characterization of activated sludge," Bioresource Technol, Vol. 90, pp. 215-20, 2003.

[18] M. M. Sozanski, E. S. Kempa, K. Grocholski, and J. Bien, "The rheological experiment in sludge properties research," Water Science and Technology, Vol. 36, pp. 69-78, 1997.

[19] F. D. Sanin, "Effect of solution physical chemistry on the rheological properties of activated sludge," Water SA, Vol. 28, pp. 207-11, 2002.

[20] G. Guibaud, P. Dollet, N. Tixier, C. Dagot, and M. Baudu, "Characterization of the evolution of activated sludges using rheological measurements," Process Biochemistry, Vol. 39, pp. 1803-1810, 2004. 